\title{
Circulación de saberes y apropiación del conocimiento local alrededor del cultivo de cacao en Talamanca, Costa Rica
}

\author{
Circulation of knowledge and appropriation of local knowledge \\ around cocoa cultivation in Talamanca, Costa Rica
}

\author{
Tania Rodríguez Echavarría \\ Universidad de Costa Rica \\ San José, Costa Rica \\ tania.rodriguezechavarria@ucr.ac.cr
}

\begin{abstract}
RESUMEN. Talamanca es un cantón fronterizo de Costa Rica que ha estado marcado por una larga historia de apropiaciones y despojo. Primero por las empresas bananeras que instalaron un sistema de enclave y recientemente por los procesos de apropiación y circulación de saberes que se han dado alrededor de la producción del cacao. El presente artículo busca estudiar este proceso, analizando específicamente el rol de organizaciones internacionales de investigación como el CATIE, cuyas intervenciones convirtieron a Talamanca, y en especial a los territorios indígenas, en laboratorios en donde se extrajo conocimiento y material genético para el mejoramiento del cacao con la excusa de hacerlo resistente a enfermedades y hongos. Talamanca se constituyó así en un laboratorio de experimentación de clones y estrategias productivas que buscaban cambiar el modo de producción indígena para hacerlo más competitivo siguiendo la lógica del mercado.
\end{abstract}

PALABRAS CLAVE. Cacao, Circulación de saberes, Comunidades epistémicas, Indígenas, Costa Rica

\begin{abstract}
Talamanca is a border canton of Costa Rica that has been marked by a long history of appropriation and dispossession. First by the banana companies that installed an enclave system and recently by the processes of appropriation and circulation of knowledge that have occurred around the production of cocoa. This article seeks to study this process, specifically analyzing the role of international research organizations such
\end{abstract}

Este es un artículo de acceso abierto publicado bajo los términos de la Licencia Creative Commons 4.0 Internacional Atribución-NoComercial-SinDerivadas.

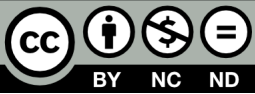


as CATIE, whose interventions turned Talamanca, and especially the indigenous territories, into laboratories where knowledge and genetic material was extracted for the improvement of cocoa with the excuse of making it resistant to diseases and fungi. Talamanca was thus established as a laboratory for experimenting with clones and production strategies that sought to change the indigenous production mode to make it more competitive by following the logic of the market.

KEYWORDS. Cocoa, Circulation of knowledge, Epistemic communities, Indigenous, Costa Rica

\section{INTRODUCCIÓN}

En el cantón de Talamanca, localizado en la provincia de Limón en la vertiente Caribe de Costa Rica, coexisten poblaciones mestizas, afrocaribeñas e indígenas Bribris, Cabécares y Ngöbe Buglé. Con uno de los índices de desarrollo humano más bajos ${ }^{1}$ del país, Talamanca, es una periferia que ha estado históricamente aislada de los centros nacionales y de los polos de desarrollo localizados en la vertiente Pacífico (Rodriguez, 2013).

Talamanca, ha estado marcada por una larga historia de despojo y de apropiaciones que data desde la conquista y que ha determinado sus dinámicas territoriales. Una de las más importantes apropiaciones territoriales, tiene que ver con la instalación de empresas bananeras estadounidenses desde finales del s. XIX, las cuales definieron el trazado fronterizo con Panamá y cambiaron la composición de las poblaciones locales al introducir a trabajadores chinos y afrocaribeños para que trabajaran en sus plantaciones (Boza Villarreal, 2014; Hall, 1985; Hall et ál., 2003; Perez Brignoli, 2000). Mientras tanto, las poblaciones indígenas tuvieron que refugiarse en las montañas de Talamanca para huir de la expansión de la actividad bananera (Bourgois, 1994). La United Fruit Company (UFCO) instauró sistemas de producción cerrados denominados "enclaves" (Hall et ál., 2003) los cuales eran concesiones políticas en donde las leyes nacionales no tenían validez y, si bien prevalecía la monoexportación y los intereses de la empresa, también convivían distintos sistemas productivos y de subsistencia (Viales, 1998, 2003, 2006, 2016). El enclave estaba aislado de los centros nacionales pero estaba conectado a través del ferrocarril al mercado

1 0,634 IDH y posición 81 de un total de 82 cantones para el 2016. 
mundial (Viales, 2006).

La historia del cacao en Talamanca, es antigua y se remonta al cultivo realizado por pueblos indígenas precolombinos para fines ceremoniales. Sin embargo, la UFCO también produjo cacao y promovió su comercialización (Boza Villarreal, 2014).

Desde finales de la década de los setentas, centros de investigación como el Centro Agronómico Tropical de Investigación y Enseñanza (CATIE) a través de su Programa de Mejoramiento Genético del cacao, empezaron a indagar sobre nuevas prácticas productivas y variedades de cacao que fueran resistentes al hongo de la monilia, el cual amenazaba la creciente actividad cacaotera.

En el marco del presente artículo, se estudiará exclusivamente la producción de cacao como otra forma de apropiación territorial que coexistió con el enclave bananero. Si bien este cultivo siempre se presenta como un proyecto productivo "verde" y exitoso", ha generado lógicas también de explotación, extracción y apropiación cultural que conviene también explorar.

Para esto se analizará el proceso de circulación de saberes liderado por la comunidad epistémica del cacao, una red de profesionales con experiencia y competencias reconocidas en este campo que buscan aportar conocimientos pertinentes para la generación de políticas (Haas, 2013, p. 351). Esta comunidad está conformada por centros de investigación como el CATIE, organizaciones intergubernamentales y organizaciones internacionales ligadas a la agricultura y a la conservación de la naturaleza.

Este artículo presenta los resultados de investigación generados en el marco del proyecto "Mitos y realidades del cacao orgánico en Talamanca", que se ha desarrollado desde el Centro de Investigación y Estudios Políticos (CIEP) de la Universidad de Costa Rica. En el marco de este proyecto se estudió la historia del cacao en Costa Rica y la gran diversidad de productores, procesadores y comercializadores de cacao del cantón de Talamanca.

Se tratará de demostrar que Talamanca fungió en el periodo de 1978-2019 como un laboratorio en donde, a través de la transferencia tecnológica y la apropiación de saberes de las comunidades indígenas, se introdujeron estrategias productivas y se probaron nuevos materiales genéticamente modificados. Lo que generó un cambio en los modelos productivos locales y en la variedad local de cacao conocida como "Matina". El conocimiento producido en 
este territorio alrededor del cacao fue exportado a otras regiones y otros países centroamericanos y africanos gracias a programas internacionales como el Programa Cacao Centroamérica (PCC) del CATIE.

Para esto, se profundizará en los procesos de circulación de saberes generados por el Programa de Mejoramiento Genético del Cacao y por el PCC del CATIE con productores indígenas de Talamanca. El artículo se concentra específicamente en estos dos proyectos, sus objetivos, intereses y formas de financiamiento. Esto con el fin de estudiar cómo se pone en práctica el proceso de intervención y de apropiación de conocimientos y cómo estos han venido transformando, lo que los productores indígenas entrevistados llaman el "modo de producción talamanqueño".

Desde el punto de vista metodológico esta investigación (20172020) realizó una importante revisión bibliográfica y de literatura gris de proyectos y programas de diferentes organizaciones que impulsaron el cultivo de cacao en Talamanca. Además, se realizaron más de 50 entrevistas a profundidad a los actores ligados a la cadena productiva del cacao. Es decir, a productores locales indígenas, no indígenas y afrocaribeños, a funcionarios del ministerio de agricultura, a técnicos del CATIE, de la Universidad EARTH, de la Unión Internacional para la Conservación de la Naturaleza (UICN) y del Banco Interamericando de Desarrollo (BID). Así como a procesadores, acopiadores de cacao, comercializadores, exportadores y chocolateros, entre otros. No obstante, para efectos de este artículo se profundizará en las y los productores indígenas residentes en los distritos de Bratsi y Sixaola en Talamanca.

A continuación, se realizará, en una primera parte, una breve reseña histórica sobre la evolución del cultivo de cacao en el Caribe Sur de Costa Rica. Posteriormente, en una segunda parte estudiaremos la transferencia tecnológica realizada por el CATIE a través de la introducción de nuevas variedades (clones) y nuevas formas de cultivo, así como las resistencias que estas intervenciones han generado especialmente en las comunidades Bribri. Y finalmente, nos centraremos en los procesos de circulación y apropiación de saberes. 


\section{TALAMANCA Y EL CACAO, UNA LARGA HISTORIA DE APROPIACIONES Y DESPOJO}

Talamanca abarca 2.809,93 km², de los cuales 30\% son territorios indígenas y el 55\% corresponden a áreas de conservación (Ver mapa 1) como el Parque Internacional Amistad-Caribe (clasificado como sitio de Patrimonio Nacional y Humano en 1983 y Reserva de Biosfera en 1982), el Parque Nacional Cahuita y el Refugio de Vida Silvestre Gandoca-Manzanillo. La presión generada sobre estas áreas protegidas por las principales actividades productivas de este cantón como lo son el turismo, los monocultivos de banano, plátano y el cultivo de cacao (Rodríguez, 2014), están causando tensiones y conflictos socio-ambientales (Llaguno Thomas et ál., 2014). Sobre todo debido a la importante contaminación que genera el uso de agroquímicos y pesticidas.

\section{Mapa 1. Cantón de Talamanca, territorios indígenas y áreas protegidas}

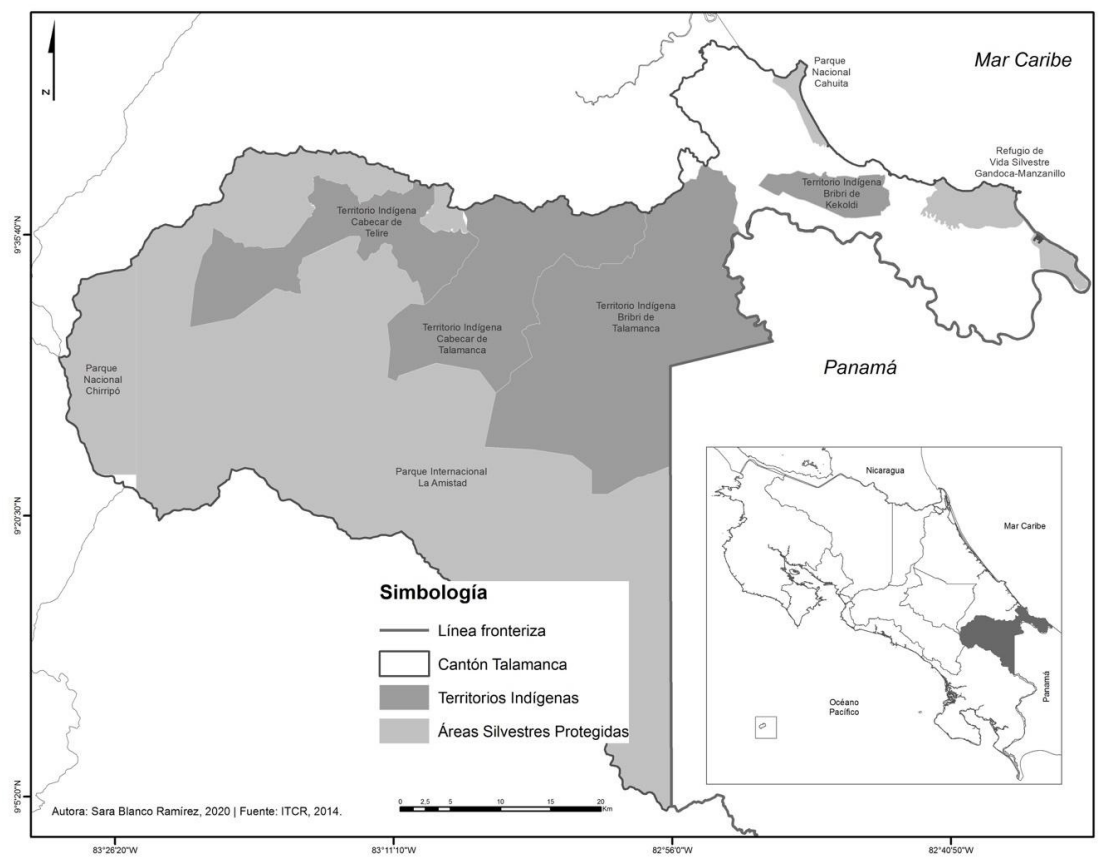

Fuente: ITCR, 2014.

El cacao del náhuatl cacahuatl, una planta nativa de América La- 
tina, tiene una larga historia con diferentes ciclos de producción que han sido estudiados por múltiples autores (Acuña, 2007; Alvarado, 1982; Guiracocha et ál., 2001; Krauss et al., 2003; MacLeod, 1996; Quesada, 1987; Somarriba et al., 2004; Somarriba y Harvey, 2018)2001; Krauss et al., 2003; MacLeod, 1996; Quesada, 1987; Somarriba et al., 2004; Somarriba \& Harvey, 2018. La historia del cacao en Costa Rica, como estas investigaciones lo demuestran, no es reciente ya que al igual que en todo Mesoamérica (Sur de México y Centroamérica) ya se producía el cacao de la variedad "Matina", para fines ceremoniales. Acuña, afirma que para la cosmovisión indígena talamanqueña la planta de cacao es conocida como Tsiru y de ella se produce una bebida sagrada utilizada en ritos de pasaje como matrimonios, muertes y nacimientos (Acuña, 2007, p. 83).

A partir de 1913, el uso comercial del cacao se le atribuye a la UFCO, la cual introduce lógicas productivas propias del monocultivo para aumentar su producción y eventualmente exportación. En este período, la producción de cacao se tecnificó mediante la incorporación de maquinaria y productos agroquímicos (Acuña, 2007). A pesar de que la UFCO en este periodo tenía el control de su producción y comercialización, la producción tradicional indígena no desaparece, esta se mantiene en las faldas de la cordillera de Talamanca (Acuña, 2007, p. 88). Paralelamente, desde la década de 1920, familias indígenas empezaron a trabajar como jornaleros en las plantaciones de cacao de pequeños agricultores afrocaribeños, desarrollando así nuevos conocimientos sobre el cultivo del cacao (Boza Villarreal, 2014).

La UFCO, inició el traslado de sus operaciones al Pacífico y a otros países desde la década de 1920, debido al agotamiento de los suelos, la búsqueda de tierras más baratas y la enfermedad de Panamá (sigatoka negra) (Royo, 2004, p. 5). Según Eduardo Somarriba (comunicación personal, 8 de abril de 2018), coordinador del Proyecto Cacao Centroamérica del CATIE, la UFCO arrendó sus fincas bananeras por $1 \$$ mensual a los capataces, los cuales sembraron cacao como una alternativa al banano. Sin embargo, afirma que la empresa vuelve al final de la década de los setenta con el fin de recuperar estas fincas al contar con variedades de banano resistentes al Mal de Panamá. Paralelamente en este periodo se dio también un proceso de toma de tierras por lo que hoy en día muchas de estas fincas quedaron en mano de asociaciones y de cooperativas que se han dedicado mayoritariamente a la producción de plátano. 
Según Boza Villarreal, no fue hasta la década de 1940 — que corresponde a la salida de la UFCO de Talamanca- que los indígenas comenzaron a cultivar cacao con fines comerciales, antes de que se convirtiera en la principal producción agrícola comercial en la década de los años cincuenta (Boza Villarreal, 2014).

Los buenos precios internacionales, generaron una creciente producción de cacao en Costa Rica. Para 1978, se llegó a producir 10381 toneladas de cacao en grano lo que correspondía a 30000 ha cultivadas (FAO, 2020). La región Huetar Caribe (Limón) en 1973, llegó a concentrar el 85\% de la producción de cacao de Costa Rica (Somarriba y Villalobos, 2013).

No obstante, este crecimiento fue truncado por la aparición en la década de los años ochenta de la epidemia de la monilia (moniliophtora roreri). Este hongo fue devastador para Costa Rica ya que en 5 años de 1978 a 1982 la producción se redujo en casi un $80 \%$ y la exportación en un 92 \%. Para 1980, por ejemplo, la producción se redujo a 5266 toneladas y a 16000 ha cultivadas (FAO, 2020). Como afirma Wilberth Philips, antiguo coordinador del Programa de Mejoramiento Genético del CATIE:

(...) hay un antes y después de la monilia... Cuando la enfermedad de la monilia llegó al país realmente acabó con la actividad cacaotera, eso sucedió no sólo en Talamanca, sino también en Upala (una zona de cultivo tradicional). Si usted conversa con la gente vieja de ahí, las plantaciones de cacao eran un cultivo común, ancestral, tradicional (uniformidad genética), de la variedad que se llama "matina" que es muy susceptible a la enfermedad (...). (comunicación personal, 13 de abril de 2018)

Como resultado de las entrevistas, se identificaron múltiples relatos alrededor de la monilia y su llegada a Costa Rica, algunos de los entrevistados residentes de Talamanca, tienen la teoría que este hongo fue introducido por la misma empresa bananera la cual según ellos, quería reducir el precio de la tierra y así apropiarse de las propiedades de los cacaoteros para volver a producir banano y plátano. Estos relatos forman parte de los imaginarios locales que se han desarrollado alrededor del cacao y de la misma empresa bananera.

Para Oscar Brenes, ex director del Programa Nacional de Cacao del Ministerio de Agricultura y Ganadería de Costa Rica (MAG), la investigación sobre cacao fue liderada por el CATIE y se centró 
mayoritariamente en temas productivos con el fin de buscar una solución a la monilia (comunicación personal, 2 de febrero 2019). En este sentido, Mariela Leandro (comunicación personal, 8 de abril 2018), aclara que a partir de 1978 los proyectos se empiezan a preocupar por generar conocimiento para hacerle frente a este hongo. Es así como se crea el Programa de Mejoramiento Genético del Cacao el cual tuvo la tarea de producir clones que fueran resistentes a la monilia y proponer formas de producción que impidieran la propagación de la enfermedad. Gracias a este programa se generaron diversas variedades que se mantienen en dos jardines clonales, uno localizado en el CATIE en Turrialba y otro en la finca la Lola en la vertiente Caribe. Es así como durante la década de los ochenta, se empiezan a introducir nuevas variedades de cacao que se creían más resistentes en las fincas de campesinos e indígenas en Talamanca. Sin embargo, los mismos técnicos del CATIE afirman que no contaban con los recursos necesarios para darle seguimiento a los productores después de estas intervenciones, por lo que no pudieron observar a largo plazo como estos nuevos materiales se comportaron en los territorios.

En Costa Rica de 1990 al 2000, las hectáreas producidas de cacao pasaron de 17420 ha a 4344 ha, y la producción pasó de 3500 toneladas a 708 toneladas, respectivamente. No es hasta al final de la década de los años noventa en donde se empieza a presentar al cacao como una alternativa productiva a los monocultivos en proyectos de cooperación los cuales aseguraban que su producción puede sacar de la pobreza a las poblaciones campesinas e indígenas. El naciente interés por este cultivo se da en un contexto muy particular, en donde mejoran los precios del cacao en grano, aumenta la demanda de la industria de chocolates finos y gourmet, y aparecen iniciativas de la cooperación internacional que buscan dar apoyo financiero, técnico y político al sector cacaotero centroamericano (Somarriba y Villalobos, 2013).

Sin embargo, la producción de cacao no volvió a ser tan competitiva como en la década de los setenta. En la actualidad, el área total de hectáreas sembradas de cacao no supera los 3286,6 ha y el $94 \%$ de las fincas tienen un tamaño inferior a las 5 ha (SEPSA, 2017). En Talamanca se encuentran el $19 \%$ del total de las fincas del país y el $22 \%$ de la producción, convirtiéndose así en el cantón del país con más fincas y donde hay más cacao sembrado (SEPSA, 2017).

En cuanto a la producción del cacao, esta se da mayoritariamen- 
te en sistemas agroforestales, es decir, sistemas que combinan diferentes cultivos (árboles frutales y maderables) y diferentes variedades de cacao. El proceso de producción del cacao cuenta con varias etapas que van desde el cultivo (por semilla o injertos), la siembra, el manejo de la plantación (poda, sombra, canales de drenaje, uso de fertilizantes, manejo de plagas y de maleza, entre otras), la cosecha, el procesamiento (acopio, fermentación del cacao en baba y secado) y la transformación en polvo o pasta ${ }^{2}$. De ahí se lleva el producto al mercado local o se exporta. El procesamiento es clave, ya que de él depende la calidad del cacao, lo que le otorga un valor agregado dentro de la cadena productiva. Es así como dependiendo de la calidad del proceso de fermentación el precio final según el acopiador puede variar de 500 a 7000 colones (SEPSA, 2017).

En Talamanca se encuentran una serie de actores que intervienen, a diferentes escalas, de la cadena productiva de cacao. Encontramos organizaciones de productores como Asociación de Pequeños Productores de Talamanca (APPTA), la Asociación de Mujeres Bribri de Talamanca (ACOMUITA) y la Cooperativa Cacao Afro (ver mapa 2). También se identificaron, familias productoras, empresarios turísticos que realizan tours de chocolate, y cuentan con tiendas especializadas en la venta de chocolate. Además, se determinaron intermediarios que compran el cacao y lo venden a empresas que lo transforman en otros productos y exportadores.

Por otra parte, hay organizaciones no gubernamentales locales como el Corredor Biológico Talamanca Caribe con proyectos que promueven el cultivo del cacao y que son financiados por organizaciones internacionales como la UICN, el BID o el CATIE. Estas organizaciones locales trabajan muy de cerca con los productores de cacao y tienen un rol de mediación o de go-between (Allard et ál., 2006, p. 307) entre los productores, las organizaciones de base y los proyectos internacionales. Su papel es clave, ya que fungen como traductores de los términos técnicos y de las estrategias que se proponen en estos proyectos. Funcionan de esta forma de mediadores porque tienen una expertise reconocida en el tema, lo que les otorga legitimidad frente a las organizaciones locales y frente a los organismos internacionales y donantes (Allard et ál., 2006, p. 310).

2 http://www.mag.go.cr/bibliotecavirtual/F01-0658cacao.pdf 
Mapa 2. Actores entrevistados de la cadena productiva de cacao en Talamanca, Costa Rica

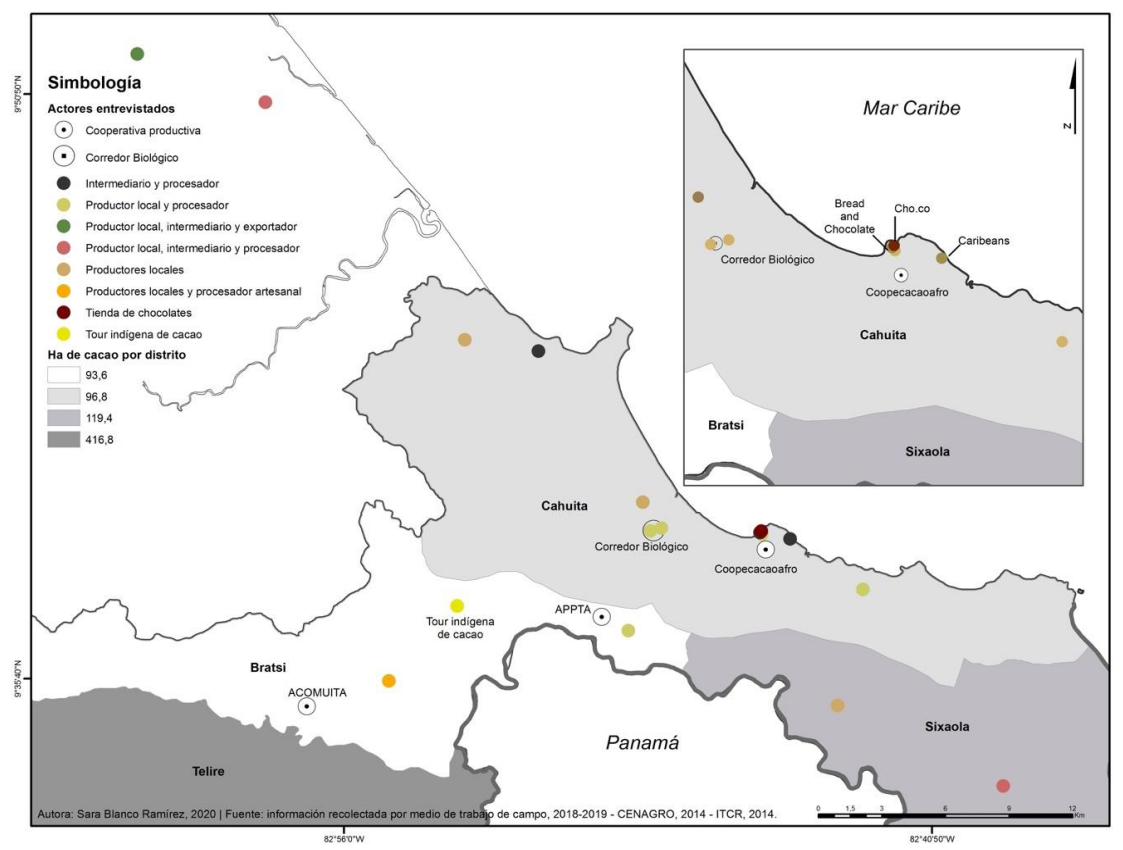

Fuente: Información recolectada por medio de trabajo de campo, 20182019; CENAGRO, 2014; ITCR, 2014.

Las organizaciones de productores con mayor visibilidad y tradición en este cantón, según los actores entrevistados, son APPTA y ACOMUITA.

APPTA es una organización indígena encargada del acopio, fermentación y comercialización del cacao. Fue fundada en 1987 con el apoyo del CATIE y reúne alrededor de 1200 asociados, entre los que se encuentran 995 productores certificados como orgánicos por la empresa certificadora Ecológica. Según Walter Rodríguez (comunicación personal, 30 de abril 2018), ex director de APPTA el $80 \%$ de los asociados son mujeres. Por su parte, ACOMUITA es una organización de mujeres indígenas Bribri que produce cacao 
para el mercado nacional e internacional. ACOMUITA se formó en el año 1991 con el objetivo de reunir a las mujeres bribri de las comunidades de Watsi y Shiroles para hacer frente a las importantes secuelas que había dejado el terremoto que tuvo como epicentro la provincia de Limón. Inicialmente fue una plataforma que buscaba incidir políticamente, sin embargo, después de la intervención del CATIE, se organizaron para cultivar sus fincas, transformarlas en integrales y focalizarse en la transformación del cacao en chocolate.

Mapa 3. Cantidad de fincas por cantón en Costa Rica y la Provincia de Limón, 2020

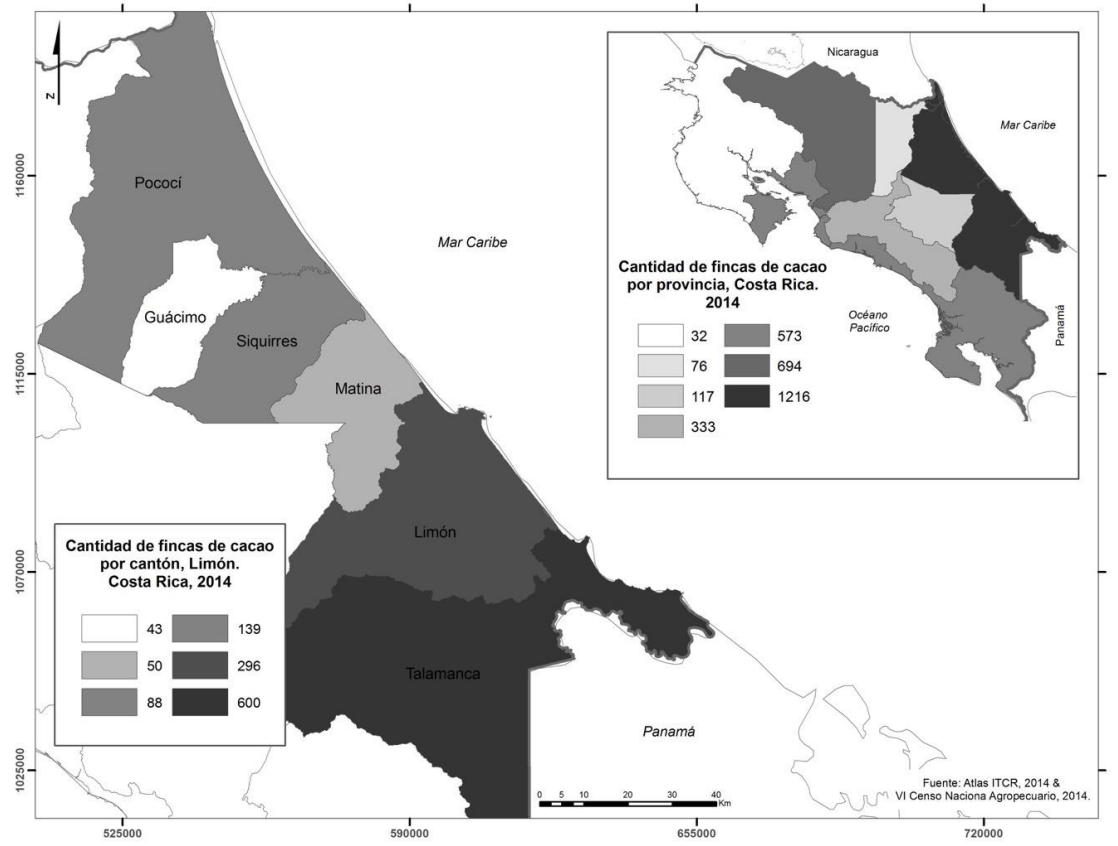

Fuente: elaboración propia a partir del Atlas (ITCR, 2014 \& VI Censo Nacioal Agropecuario, 2014.

En la actualidad, en Talamanca se encuentran alrededor de 600 fincas donde se siembran aproximadamente 725,5 ha de cacao (SEPSA, 2017). El material genético que más se siembra son de variedades tributarias que hacen que el cacao producido sea considerado como "cacao fino" según las estipulaciones de la Organización 
Internacional del Cacao (ICCO). Una de las principales problemáticas es la baja productividad de las fincas y su alta vulnerabilidad frente a enfermedades (SEPSA, 2017). Es así como en Costa Rica según los datos de la FAO, en el 2018 únicamente se produjo 550 toneladas de cacao en grano $(\mathrm{FAO}, 2020)$ y el $59 \%$ de la producción de las fincas de la región Huetar Caribe está destinado al mercado local. No obstante, mucho del cacao producido en Talamanca es procesado por APPTA y de ahí se exporta en grano seco mayoritariamente a Europa. La distribución del cacao en el país se puede observar en el mapa 3. Este mapa visualiza como la mayor cantidad de fincas están localizadas en la vertiente caribe y en la provincia de Limón, en Talamanca.

La producción de cacao en Talamanca se concentra en la parte alta de la cuenca del río Sixaola en los territorios indígenas bribris y cabécares. Gran parte de esta producción se realiza en fincas integrales de 1 a 10 ha (Rodríguez, 2014, p. 174).

\section{¿POR QUÉ TALAMANCA? UN LABORATORIO PARA LA COOPERACIÓN Y PARA LA EXPERIMENTACIÓN}

La región fronteriza entre Costa Rica y Panamá y en especial, Talamanca es un caso pionero de cooperación binacional y el "ejemplo a seguir" en materia de cooperación ambiental. Marta Pérez de Madrid (comunicación personal, 6 de abril de 2018), ex coordinadora del Proyecto de Adaptación y Cambio Climático de la UICN, afirmó que esta región fronteriza cuenta con las condiciones "ideales" para poner en práctica proyectos. Estas condiciones son la ausencia de conflictos fronterizos, la simetría cultural y la proximidad que existe entre las instituciones. Además, esta región atrae a la cooperación por su riqueza ambiental, la presencia del primer parque binacional del Istmo, y la existencia de un marco jurídico precursor para cooperación binacional. De esta manera, Talamanca representa no sólo un entorno ideal para la cooperación a nivel político, sino también a nivel ambiental, siendo este un tema central en un cantón donde el $80 \%$ del territorio se encuentra bajo alguna categoría de conservación. Para los entrevistados fue claro que estas condiciones fueron tomadas en cuenta al momento de seleccionar esta región para la ejecución de sus proyectos.

El creciente número de iniciativas destinadas a establecer proyectos de conservación y gestión de los ecosistemas compartidos 
en Talamanca pone de manifiesto un claro interés internacional (Franklin, 2007, p. 9) y han convertido a Talamanca en un verdadero laboratorio de la cooperación (Rodríguez Echavarría, 2018, 2019). Desde inicios de la década del 2000 se pueden identificar al menos tres proyectos de la $\mathrm{UICN}^{3}$, una Alianza público-privada Sixaola-Changuinola para el desarrollo (2009-2013) financiada por el Agencia de Ayuda para el Desarrollo de los Estados Unidos (AID), la cooperación alemana (GIZ) y la empresa bananera Chiquita, el Programa de Parques en Peligro de The Nature Conservancy (hasta el 2008), el Proyecto de Competitividad y Ambiente en los territorios productores del cacao en Centroamérica (desde el 2010) del CATIE y un préstamo dado a Costa Rica y una donación a Panamá otorgados por el Banco Interamericano de Desarrollo en temas ambientales (BID-GEF) y agropecuarios (BID-MAG) (Rodríguez, 2014, p. 284).

Todos estos proyectos y programas promovieron la gestión integral de la cuenca del río Sixaola en Talamanca y fomentaron el desarrollo de emprendimientos productivos "verdes" en donde se destinaron muchos recursos a proyectos de fincas integrales productoras de cacao. En el caso de los proyectos de la UICN y de TNC todos se implementaron en Talamanca y posteriormente se replicaron en otros territorios localizados en Centroamérica, Suramérica, África y Asia a través de las antenas locales de estas organizaciones internacionales (Rodríguez, 2014).

En cuanto a los proyectos del CATIE, la escogencia de trabajar en Talamanca se debió a que este territorio es óptimo para la producción de cacao. Ya que no sólo tiene el clima ideal, sino que está habitado por poblaciones indígenas y afrodescendientes que cuentan con la tradición y la experiencia para cultivar cacao.

El presidente de la cooperativa Cacao Afro Rl, Edgar Campbell, relataba que la producción de cacao había sido una tradición para sus familias, las cuales por la llegada de la monilia habían tenido que abandonar este cultivo. Pero con el apoyo e intervención de proyectos de cooperación del Instituto Interamericano para la Cooperación en Agricultura (IICA), de la UICN, el CATIE y la EARTH

3 Proyecto Alianzas (2004-2011), Proyecto para la buena gestión del Agua y la adaptación al cambio climático en las cuencas transfronterizas (2010-2019) y el Proyecto Building River Dialogue and Governance (BRIDGE) 2010-2016. 
muchos productores estaban volviendo a interesarse en el cacao. En palabras de Edgar Campbell:

Queremos reconstruir los valores que nos hicieron un pueblo económicamente independiente. Queremos fomentar la solidaridad, ser amos del cacao y no esclavos del cacao. Mejorar el valor agregado para mejorar la calidad de vida de los productores. Que la producción de cacao permita un tejido social para rearmar y reorientar las relaciones ya que el cacao permite unir la cuenca alta-media-baja y la frontera. (comunicación personal, 19 de mayo, 2018)

El cacao se presenta, así como una promesa de desarrollo, no obstante, conviene preguntarnos, ¿por qué un cantón que produce tan poco cacao como lo es Talamanca es considerado como un territorio estratégico para el sector cacaotero? Si bien Talamanca, prácticamente ya no produce cacao, lo que ofrece es un escenario ideal, en donde convergen la naturaleza, las comunidades indígenas y el cacao, características que justifican y legitiman la existencia de proyectos de cooperación frente a los donantes. Se promueve así, un cultivo "verde" con poblaciones vulnerables, lo que garantiza el apoyo de empresas chocolateras, las cuales responden a lógicas de responsabilidad empresarial que se aprovechan de estas características para dotar al producto de etiquetas como "justo", "orgánico" y "tradicional", otorgándole así un valor agregado en el mercado internacional.

\section{CIRCULACIÓN DE SABERES, COMUNIDADES EPISTÉMICAS Y FORMAS DE APROPIACIÓN DEL CONOCIMIENTO}

Diana Ojeda (2016), define despojo como "un proceso violento de reconfiguración socioespacial y, en particular, socioambiental, que limita la capacidad que tienen las comunidades de decidir sobre sus medios de sustento y sus formas de vida" (p. 21). El capitalismo busca así "colonizar nuevos territorios" para integrarlos dentro de sus operaciones a través de lógicas diversas que van desde actividades extractivas tradicionales como los monocultivos, hasta el uso de "patentes, insumos tecnológicos, instrumentos financieros y apropiación del conocimiento"(Gago y Mezzadra, 2015, p. 41). 
Es así como Talamanca ha estado marcada por procesos de despojo y apropiación tanto de recursos como de saberes. Se pueden identificar dos procesos claves de apropiación (que no son los únicos), el primero que implica una apropiación territorial, que se lleva a cabo con la instalación de las empresas bananeras y del sistema de enclave. El segundo tiene que ver con los procesos de apropiación de saberes, que se llevan a cabo por organizaciones internacionales, a las cuales no les interesa cómo o cuánto cacao se produce, sino cómo, experimentando en este territorio, se genera conocimiento sobre cacao que puede ser replicable y atractivo para otros territorios y organizaciones. Es decir, hay un cambio en la forma de extracción ya no de materias primas o commodities sino de conocimiento y de saberes locales.

Al analizar los procesos de apropiación y de circulación de saberes que se llevaron a cabo en Talamanca por organizaciones como el CATIE podemos determinar que este no es lineal o top-down (de arriba hacia abajo). Este proceso de apropiación es aún más complejo y podría definirse como un proceso circular que implicaría varias etapas: 1) investigación e identificación de prácticas productivas y extracción de material genético en los territorios; 2) experimentación, generación de clones, de estrategias de intervención y concepción de proyectos; 3 ) intervención, transferencia tecnológica y de conocimiento (conceptos híbridos, resultantes de combinar conocimiento local con agendas globales); 4) replicar resultados en otros territorios. Esto debido a que, para intervenir y realizar el proceso de transferencia tecnológica, se tuvo primero que investigar y recuperar material genético que después sería la base para la creación de los clones que posteriormente serían introducidos.

Se estudiará este proceso y cómo las diferentes técnicas de intervención y de apropiación del conocimiento generaron metodologías y conceptos que llamaremos híbridos, ya que estos son el resultado de un proceso de combinación de saberes locales, conocimiento científico y de agendas políticas. Se indagará cómo estos conceptos fueron re-introducidos en las mismas comunidades que los inspiraron. Y finalmente, se resaltará cómo estas intervenciones fueron percibidas por los productores locales y el impacto que tuvieron en sus prácticas productivas y en sus fincas. 


\section{Iniciativas de transferencia tecnológica y técnicas de apropiación del conocimiento}

El CATIE, es un organismo internacional que funciona tanto como un centro de investigación, de educación superior y de cooperación técnica para el desarrollo, la gestión integrada de la agricultura y de los recursos naturales. Su sede se encuentra en Turrialba, Costa Rica, no obstante, desarrolla intervenciones en más de 14 países en el continente americano (Centroamérica, México, el caribe, Colombia y Bolivia). Tiene una gran diversidad de proyectos de investigación y cooperación en temáticas muy diversas como seguridad alimentaria, gestión del agua, cuencas transfronterizas, cambio climático, sistemas agroforestales, cacao, entre otros.

Según Eduardo Somarriba (comunicación personal, 8 de abril de 2018), coordinador de varios proyectos del CATIE, desde finales de la década de los ochenta, el CATIE se ha preocupado por generar "opciones tecnológicas" para Talamanca alrededor del cacao, árboles frutales, plátanos, tubérculos, entre otros. Gracias al financiamiento del Banco Mundial estuvieron "experimentando con productores en alrededor 80 fincas" (Somarriba, comunicación personal, 8 de abril de 2018). En el territorio indígena tuvieron proyectos como el de Cacao orgánico y biodiversidad financiado por el Banco Mundial, otros patrocinados por el Programa de Global Environmental Facilities y otros de Captura de carbono. Todos estos anteriores al Proyecto Cacao Centroamérica (PCC).

Desde la década de los años 80 el CATIE emprendió un proceso de transferencia tecnológica alrededor del cultivo del cacao, entendiendo por transferencia tecnológica a "la transferencia del capital intelectual y del know-how entre organizaciones con la finalidad de su utilización en la creación y el desarrollo de productos y servicios viables comercialmente" (Soto Noriega, 2006, p. 2).

El Programa de Mejoramiento Genético del Cacao se ha enfocado desde hace más de 30 años "en crear variedades de cacao mejoradas, con el propósito de ponerlas a disposición de los productores para así aumentar su nivel de vida" (CATIE, 2019). Es así como ha generado una importante colección de clones de cacao a partir del material genético encontrado en Talamanca (primera y segunda fase del proceso de apropiación propuestas en este artículo). Joel Buitrago, productor indígena de cacao relataba que los técnicos iban de finca en finca "apoderándose del material genético" 
(comunicación personal, 29 de abril de 2018).

Desde el 2007 el Programa seleccionó seis clones que están siendo distribuidos en Centroamérica (CATIE-R1, el CATIE-R4, el CATIE-R6, el CC-187, el ICS-95 T1 y el PMCT-58) por ser considerados variedades tolerantes a la monilia, cumplir con los requerimientos de la ICCO y tener un alto rendimiento, lo cual permite garantizar "un suministro más estable de cacao para la industria" (CATIE, 2019).

Para W. Philips (comunicación personal, 13 de abril de 2018), ex coordinador de este programa, el mantenimiento de este y de la colección es muy costoso ya que el gasto asciende a $\$ 400$ mil anuales y solo cuentan con $\$ 10$ mil que aporta la World Cocoa Foundation. Es por esto que se han ideado múltiples proyectos a través de los años para sostener al programa, sus colecciones y al mismo tiempo responder a los intereses de los donantes. Los cuales en su mayoría son empresas chocolateras transnacionales como Mars, Nestlé o Hershey's, así como instituciones internacionales como North Sound Dietetic Association (NSDA) o la cooperación coreana $(\text { KOLFACI })^{4}$.

Entre el 2008-2012 el CATIE formuló el Proyecto "Competitividad y Ambiente en los Territorios Cacaoteros de Centroamérica" conocido popularmente como el "Proyecto Cacao Centroamérica" (PCC) (Somarriba y Villalobos, 2013) el cual fue financiado por el gobierno de Noruega ( $\$ 5$ millones) por una duración inicialmente de 5 años (después tuvo una extensión de 3 años más) en Centroamérica. Este proyecto introdujo "la última generación de clones con tolerancia a la moniliasis, buen rendimiento y alta calidad" (Somarriba y Villalobos, 2013, p. 5). Tenía por objetivo elevar la competitividad de las fincas cacaoteras, mejorar el funcionamiento empresarial y asociativo, generar alternativas para las familias productoras para salir de la pobreza, proveer servicios ambientales (Somarriba et ál., 2013, p. 111) y así "satisfacer las exigencias de mercado" (Somarriba y Villalobos, 2013). Desde el PCC se desarrollaron procesos de capacitación denominados "Escuelas de Campo" con familias productoras de cacao en Talamanca con el fin de mejorar su producción (poda, sombra, etc.) (Rodríguez, 2014, p. 238) y promovió una red de 38 jardines clonales en la región.

4 Información suministrada por la página oficial del CATIE y complementada con la entrevista generada al señor W. Philips el 13 de abril 2018. 
El PCC generó también, importantes procesos de negociación y cooperación haciendo incidencia política en los gobiernos locales y nacionales, generando mesas y programas nacionales de cacao. Es importante aclarar que el PCC fue un proyecto de intervención, no de investigación. Es decir, este proyecto se concentró en las fases 3 y 4 del proceso de apropiación propuesto en este artículo, a diferencia del Programa de mejoramiento genético de cacao el cual se especializó en las fases 1 y 2.

APPTA por su parte cuenta con 2 hectáreas plantadas con clones del CATIE. Walter Rodríguez (comunicación personal, 30 de abril de 2018), ex presidente de APPTA, afirmaba que el aporte del CATIE y del PCC fue clave para la generación de los viveros con los que cuenta la asociación, en donde se reproducen y distribuyen los materiales del CATIE a aproximadamente 1200 familias productoras de Talamanca de las cuales $94 \%$ son indígenas. Él afirma que si bien, estas variedades son tolerantes a la monilia, estas no son resistentes. Según Rodríguez, el CATIE quiso patentar ese material, empero, él afirma que ese material "nos pertenece a todos" ya que estas organizaciones también se financian con fondos públicos y el material procedía de Talamanca. No obstante, Somarriba afirma que más bien para el CATIE siempre fue una preocupación que la colección fuera un patrimonio de acceso libre siguiendo los tratados suscritos por la FAO (comunicación personal, 8 de abril de 2018).

Para Somarriba (comunicación personal, 8 de abril de 2018),, el PCC tuvo un gran impacto en Talamanca y en la región, por un lado, promovió: 1) la organización comunal, fortaleciendo según él a organizaciones como ACOMUITA y APPTA; 2) logró importantes cambios en el modelo de producción en Talamanca a través de la transferencia tecnológica, cambiando las plantas y su reproducción por semilla, por clones e injertos. Además, las escuelas de campo mejoraron las técnicas de poda y de sombra. 3. Asimismo, el PCC produjo mucho conocimiento y documentación. Según Somarriba (comunicación personal, 8 de abril de 2018), se contó con alrededor de 75 estudiantes realizando investigación, por lo que se generó una gran cantidad de publicaciones científicas, manuales de campo, programas de radio y videos. Es importante también destacar que el PCC promovió actividades ecoturísticas alrededor del cacao. 


\section{Comunidades epistémicas, conocimiento experto y conceptos híbridos}

\section{Comunidades epistémicas y grupos expertos en el sector cacaotero}

Los proyectos del CATIE y de otros organismos internacionales (UICN, BID, TNC, etc.) en materia agrícola en Talamanca sustentan y legitiman sus acciones porque son el resultado de procesos de investigación científica. La ciencia tiene un rol central en el sector cacaotero ya que esta respalda las recomendaciones y las intervenciones.

Existe una gran variedad de actores a los que la comunidad internacional ha asignado la tarea de producir datos científicos. Estos agentes, comúnmente denominados "comunidades epistémicas", incluyen no sólo organizaciones como el CATIE, la UICN, la ICCO o el IICA, sino también grupos de expertos (muchos de ellos consultores internacionales) y científicos.

Por ejemplo, la Organización Internacional del Cacao (ICCO) creada en 1973, es un espacio clave en donde se toman importantes decisiones y se establecen los lineamientos que afectan al sector cacaotero mundial. Esta organización está compuesta por países miembros productores y consumidores de cacao. Organizaciones como el CATIE le brindan asesoría y participan como expertos en algunas de sus reuniones y foros.

El término comunidad epistémica fue introducido a finales de los años noventa por autores como Emmanuel Adler y Peter Haas ( Haas, 1992; Meyer y Molyneux-Hodgson, 2011) para designar a una "red de profesionales con experiencia y competencia reconocidas en un campo particular que pueden aportar conocimientos pertinentes para la generación de políticas en un campo en cuestión" (Haas, 2013, p. 351). El estudio de las comunidades epistémicas es pertinente porque permite comprender cómo funcionan "los canales a través de los cuales las nuevas ideas fluyen de las sociedades a los gobiernos y a través de los países" (Bossy y Evard, 2010, p. 140).

Estas comunidades epistémicas comparten técnicas, métodos científicos y creencias normativas, es decir, criterios intersubjetivos que posteriormente justificarán la acción social de sus miembros (Meyer y Molyneux-Hodgson, 2011, p. 142). Las soluciones pro- 
puestas por esta comunidad son una construcción colectiva de un círculo bastante cerrado de expertos (modelo tecnocrático), son también el resultado de una demanda política, es decir, de una necesidad de los responsables de la toma de decisiones que a veces no tienen ni el conocimiento ni los medios para producirlo (Meyer y Molyneux-Hodgson, 2011, p. 142).

Los expertos internacionales alrededor del cacao forman así una comunidad epistémica que tiene influencia a escala internacional y en la política pública de los Estados que intervienen. Esta comunidad epistémica del cacao, está conformada por organizaciones internacionales (CATIE, UICN, EARTH, IICA, entre otras), organizaciones intergubernamentales (OIG) (ICCO, FAO, PNUD), grupos de expertos y grupos de reflexión o "Think Tanks" (Medvetz, 2009). Los grupos de reflexión "ocupan espacios más reservados" y se diferencian de los centros de investigación universitarios en que tienen como objetivo influir en las decisiones políticas mediante productos como documentos breves de política (policy brief) o informes de política.

En este sentido es importante hacer una distinción entre científicos y expertos, ya que los científicos son productores de conocimientos que a menudo están vinculados al mundo académico. Los expertos son, "individuos con habilidades y/o conocimientos especializados" (Hassenteufel, 2011, p. 217) que actúan como intermediarios entre "un espacio de conocimiento y un espacio de toma de decisiones (un ámbito de políticas públicas)" (Hassenteufel, 2011, p. 218).

El CATIE al ser un centro de formación, de investigación y una organización, funge tanto como un centro científico y un grupo de expertos que incide en diferentes instancias gubernamentales y en espacios de debate internacional. Esto debido a que los procesos de debate y de creación de conocimientos suelen desarrollarse en foros y cumbres internacionales (Conferencia Mundial de Cacao) sobre temas específicos ligados al cacao en donde los científicos y expertos del CATIE son frecuentemente invitados. Además, el CATIE gracias a su estructura descentralizada, difunde los conocimientos, los instrumentos de acción (metodologías y conceptos) y los argumentos que justifican sus orientaciones en diferentes países.

Este complejo engranaje que articula lo local con lo internacional, permite entender cómo estas organizaciones internacionales 
están aplicando las mismas estrategias y conceptos a nivel local en diferentes partes del mundo reproduciendo así la misma "receta". Esto es el caso de las estrategias aplicadas por el PCC en Centroamérica y en otras partes del mundo como Africa. Esta receta se reduce a tres grandes pasos: 1 ) difusión de clones y formas de cultivo; 2) educación y formación (Escuelas de Campo); y 3) negociación-cooperación, es decir incidencia política con autoridades nacionales y locales.

En este contexto, las comunidades epistémicas tienen una influencia creciente en lo local, nacional y regional. A escala mundial, producen conocimientos, conceptos que llamaremos híbridos (que estudiaremos más adelante), así como recomendaciones que tienen por objeto dar respuestas a problemas que consideran son compartidos por todos. A nivel nacional y local, estas comunidades han desempeñado el papel de difusoras y traductoras de las recomendaciones acuerdos internacionales.

\section{Conceptos híbridos, nombrar lo que ya existe}

A través de las capacitaciones y las numerosas intervenciones de los proyectos como, Cacao y Biodiversidad, el PCC y el Programa de Mejoramiento Genético, múltiples metodologías (poda, sombra, etc.) y conceptos pensados y desarrollados desde este grupo de expertos, han circulado y se han difundido en Talamanca y son hoy en día utilizados de forma cotidiana por los mismos productores de cacao. No obstante, estos conceptos combinan una gran diversidad de saberes, por eso los llamaremos híbridos ya que estos son el resultado de un proceso que articula tantos saberes locales, con conocimiento científico y agendas políticas globales (acuerdos internacionales, recomendaciones de comunidades epistémicas e intereses de los donantes).

Es así como conceptos importados como los de agroecología, agricultura familiar y de fincas integrales han venido a caracterizar dinámicas previamente existentes en los territorios. Ya que el modelo que los productores indígenas denominan como "modelo de desarrollo talamanqueño" o "sistema de producción indígena" se hacía en fincas ya de por sí libres de agroquímicos, "integrales", agroecológicas y cultivadas por familias indígenas. Varios estudios demuestran que el cacao talamanqueño es un cultivo tradicional- 
mente agroecológico y adecuado para pequeños productores (Salazar-Díaz, 2011).

El "modelo de desarrollo talamanqueño", ha sido ampliamente descrito y estudiado (Acuña, 2007; Borge y Castillo, 1997; Villalobos y Borge, 1995), la particularidad de este modelo se debe a cuatro aspectos: la forma de producción, la relación con la naturaleza, la tenencia de la tierra, y la organización tradicional bribri. Este modelo socio-productivo se basa en un sistema de producción agroecológico en donde coexisten árboles frutales, cultivos convencionales (banano y plátano) y agricultura orgánica, así como la vegecultura y, en menor medida, la caza, la pesca y la recolección (Acuña, 2007). Tiene como unidad productiva la finca integral que es cultivada por la familia indígena. Este sistema de subsistencia se basa en una relación de respeto y protección de la naturaleza que permite "conservar los recursos naturales y reforzar elementos de la cultura productiva indígena talamanqueña" (Acuña, 2007). En cuanto a la tenencia de la tierra, la cultura bribri es matrilineal ya que es a través de la madre que se transmite la lengua, la cultura, la propiedad de la tierra y la pertenencia a uno de los cinco clanes existentes (Chavarochette y Rodriguez, 2020). Este sistema se sostiene en "el modelo agroforestal talamanqueño ancestral" en donde el cacao es uno de sus pilares (Acuña, 2007).

Los conceptos difundidos por el CATIE, la UICN y el mismo $\mathrm{BID}$, vienen a introducirse en estas comunidades como buenas prácticas. Si analizamos el proceso de circulación de los saberes identificados, esto podría ser parte de un proceso bottom-up en donde estas organizaciones se apropian de ideas y saberes locales para construir conceptos "híbridos" que después devuelven a las mismas comunidades que los inspiraron.

La agroecología es un concepto en disputa y puede tener muchas expresiones, el policultivo es una de ellas. Sin embargo, policultivo y agroecología no son sinónimos, policultivo es un concepto pensado desde el capitalismo que hace referencia a la producción y al mercado, mientras que la agroecología tiene más que ver con lógicas de subsistencia y la búsqueda del bienestar de una comunidad. En realidad, la agroecología es una disciplina que busca estudiar, diseñar y manejar agroecosistemas para que sean productivos y permitan la conservación de la naturaleza tomando en cuenta elementos culturales y sociales (Altieri, 2009). Es decir, busca pro- 
mover ambientes balanceados, rendimientos sustentables, la fertilidad del suelo, y la regulación natural de las plagas a través del diseño de agroecosistemas diversificados y el uso de tecnologías de bajos insumos (Altieri, 2009, p. 30). De esta forma, promueve el policultivo, la agroforestería y la rotación de cultivos integrando los animales y los productores. La agroecología busca generar una visión integral en donde su primer lugar de análisis es la parcela o la finca campesina (Sevilla, 2006) y busca en teoría tomar en cuenta las problemáticas locales por lo que ha venido según Giraldo (2018) a: "nutrir las luchas y a aglutinar los esfuerzos populares para enfrentar la injusticia distributiva, la depredación ambiental, la insalubridad alimentaria, el hambre y la desnutrición, y el desplazamiento de familias campesinas a las ciudades" (p. 124).

La visión propuesta por el CATIE hace referencia a aspectos técnicos y tecnológicos que se deben de considerar para llamar a una finca "agroecológica" ( Moreno, 2011) pero que en la práctica no lo es. Para el CATIE para ser "agroecológica" una finca debe: tener al menos $70 \%$ de sombra natural, que se cultive de forma diversificada incorporando maíz, plantas de plátano, yuca, frutales y maderables. Se recomienda además la aplicación de fertilizantes orgánicos, controladores biológicos y fungicidas orgánicos. Es así como las intervenciones pensadas por el CATIE aportan elementos técnicos, pero no profundizan en los aspectos políticos que implican cuestionar las relaciones de poder y el modelo de desarrollo dominante. Esta visión más política plantea la reivindicación de las prácticas agroecológicas, de la cosmovisión y de los modos de vida indígenas como un "sistema ancestral autosuficiente" (Salazar-Díaz, 2011, p. 29) que permite la protección de la naturaleza y no está sujeto a los procesos de acumulación y de despojo.

Es interesante también evidenciar que para los productores indígenas la agroecología es más un movimiento que reivindica sus prácticas tradicionales y su relación con la tierra y prefieren utilizar este término, más que el término de agricultura orgánica, porque muchos consideran que este concepto está determinado por el mercado y en especial por las empresas certificadoras. Este fue el caso de Joel Buitrago el cuál describió su finca como agroecológica explicando que esto era diferente a ser orgánico porque para ser orgánico implicaba certificarse (comunicación personal, 29 de abril de 2019). Si bien APPTA y ACOMUITA han acudido a pro- 
cesos de certificación para la exportación de cacao orgánico todos cuestionan lo costoso y largo que es este proceso. Walter Rodríguez también hizo uso de la noción de agroecología para describir las fincas, empero, para él, esta noción implicaba además del policultivo, proteger la diversidad y la seguridad alimentaria de Talamanca (comunicación personal, 30 de abril de 2018).

Otro concepto clave de los textos del CATIE es el de "agricultura familiar" o campesina. Acuñado por el Comité Interamericano de Desarrollo Agrícola durante la Conferencia Interamericana de Punta del Este en 1959, en el marco del proceso de reforma agraria (Carmagnani, 2008), fue utilizado para referirse a un tipo de tenencia de la tierra en donde se define como unidad productiva "las tierras que sirven de sustento a una familia", la cual hace uso de técnicas locales y se caracteriza por tener un tamaño pequeño (predio) (Carmagnani, 2008). Este concepto fue recuperado por la FAO como un sistema agrícola diversificado en donde se producen productos tradicionales que son vendidos en mercados locales generando empleo y salvaguardando la agrodiversidad (FAO, 2020) . Para el CATIE es un "componente clave para el desarrollo territorial" ya que vincula a las familias rurales con el desarrollo, la seguridad alimentaria y la conservación de la agrodiversidad.

La agricultura familiar es vista como una buena práctica por el Ministerio de Agricultura y Ganadería (MAG) de Costa Rica, Nelson Kopper, director regional del MAG durante una reunión de Productores de Cacao en Cahuita, Limón, felicitaba a un productor por haber incluido en su finca a toda su familia:

¡es la familia! La familia es la que tiene que estar a cargo de la empresa que es la finca. Todos tenemos funciones. Todos tenemos funciones dentro de esta empresa. Todos somos importantes. La esposa, el esposo, los hijos, las hijas, nietos, yernos, ¿qué se yo? Eso es otra cosa para ir mejorando el proceso y el manejo empresarial que se tiene que dar. (comunicación personal, noviembre de 2019)

La agricultura familiar es un elemento presente en todos los proyectos de cacao del CATIE así como en el mismo Programa Nacional de Cacao (2018-2028) en Costa Rica. En donde se presenta como una solución que permite reducir el desempleo, el costo de

5 Plataforma de conocimientos sobre Agricultura Familiar http://www.fao.org/ family-farming/home/es/. 
la mano de obra y la pobreza asegurando la conservación de la naturaleza. También a través de ella se promueve la participación activa de mujeres e indígenas en las actividades cacaotera. Sin embargo, este tipo de agricultura ya era objeto de los modos de producción indígenas en Talamanca, en donde toda la familia participa en la finca (Borge \& Castillo, 1997; Bozzoli, 1979; Guevara, 2011). Además, la agricultura familiar ha sido criticada ya que muchos autores cuestionan su eficiencia (Rodríguez-Sperat \& Emanuel-Jara, 2018) y otros afirman que esta promueve el trabajo infantil y la violación de los derechos laborales al no respetar las jornadas de trabajo (8 horas) y al no dar a los trabajadores un salario, vacaciones, entre otras.

\section{COLONIZACIÓN DE SABERES: CONOCIMIENTO CIENTÍFICO VS SABERES LOCALES INDÍGENAS}

La introducción de los clones y del sistema de injerto en Talamanca generó resistencias en los productores indígenas no sólo por el riesgo que representaba cambiar sus árboles de cacao "criollo", ya en edad de producción, por nuevas variedades que, para llegar a su máxima productividad, requerirían esperar al menos 4 años, sino porque también implicaba introducir prácticas y lógicas diferentes y muchas veces contrarias a sus imaginarios y modos de producción. Además, no se tomó en cuenta, ni la cosmogonía indígena ni los conocimientos tradicionales ligados a la producción del cacao. Eduardo Somarriba (comunicación personal, 8 de abril de 2018) coordinador del PCC, afirma que esta "desconfianza cultural" fue para el CATIE una de las principales dificultades. Para él hubo un choque entre "la visión cosmológica del cacao y la versión mercantilista" ya que, según él, para las comunidades indígenas existen una serie de tradiciones que él llama, "protocolos", en cuanto a cómo cultivar el cacao. Esto generó desconfianza e importantes tensiones entre los productores y el CATIE. Para Somarriba esto produjo una barrera cultural entre el Sikua (gente blanca-no indígena en bribri) y los indígenas que fue imposible de superar.

Esto debido a que para los productores indígenas bribris el cacao es un elemento clave en su cultura, puesto que este siempre ha formado parte de sus vidas y tradiciones. Para Faustina Torres (comunicación personal, 30 de abril de 2018) de ACOMUITA "siempre ha habido cacao en nuestras fincas, nosotros nacimos del cacao" y afir- 
ma que siempre lo han cultivado sin agroquímicos, pero "es hasta ahora que los técnicos del CATIE y del Ministerio de Agricultura le pusieron el nombre de agroecológico y a sus fincas les adjuntaron el adjetivo de integrales". Ella concuye diciendo que "ellos vinieron con tecnicismo y nosotras con la práctica".

Del cacao se produce una bebida ceremonial que Joel Buitrago (comunicación personal, 29 de abril de 2018), productor indígena de cacao, denomina "sangre de nosotros" ya que es la primera bebida que les da Sibü (dios bribri). Esta bebida está presente en todas sus ceremonias y hoy en día se ha vuelto un elemento central de las actividades turísticas denominadas "Tours del chocolate".

Los productores indígenas entrevistados, afirman que las intervenciones del CATIE fueron verticales o top-down, ya que durante las capacitaciones y otros intercambios se les dijo cómo debían cultivarlo y procesarlo. Según, Joel Buitrago (comunicación personal, 29 de abril de 2018), con la llegada de la monilia se les dijo "corten sus árboles y planten estos otros, simplemente porque se los digo, así que créanme". Además, para él, no hubo un reconocimiento de los saberes locales en cuanto a la producción de cacao: "Ustedes no saben podar y nosotros toda la vida lo habíamos hecho". Para él, este "acompañamiento técnico" era más una intervención unilateral en donde se subordinaron los conocimientos locales frente al conocimiento experto. Esta actitud no fue exclusiva de los técnicos del CATIE, Joel Buitrago (comunicación personal, 29 de abril de 2018) afirma que "las instituciones del gobierno no les interesa el conocimiento indígena", haciendo referencia al Ministerio de Agricultura y Ganadería de Costa Rica.

Para Faustina Torres (comunicación personal, 30 de abril de 2018) la calidad del cacao de Talamanca viene del "sistema de producción indígena", el cual no están dispuestas a cambiar. Para ella, el Proyecto de Cacao Orgánico y Biodiversidad y el PCC del CATIE "hicieron mucha investigación que sirve para ellos y poco para nosotros". De igual manera, ella insiste en que "trajeron clones de cacao que no funcionaron, fueron un experimento". De esta forma, denuncia que los técnicos del CATIE no aceptaban que ellos tampoco conocían el verdadero impacto que tendrían sus intervenciones ya que "ellos estaban experimentando y aprendiendo" de esos materiales que introdujeron en Talamanca. Asimismo, afirma que estos clones tienen una calidad menor que el cacao que ella denomina "criollo" puesto que estos producen "semillas más aplastadas, pe- 
san menos y tienen menos grasa, por lo que requieren de más cacao para hacer un kilogramo". También varios productores plantearon que los clones implican más trabajo y cuidado pues requieren de más podas y aun así siguen siendo susceptibles a la monilia.

No obstante, Somarriba (comunicación personal el 8 de abril de 2018) por su parte, califica el sistema de producción indígena como "poco eficiente" y considera que existe una "inercia" puesto que no se invierte el trabajo y el tiempo requerido para aumentar la productividad de la finca. Para hacerle frente a esta desconfianza, el CATIE contrató a actores locales que habían trabajado en ONG locales para que jugaran un rol de intermediarios y así legitimar sus intervenciones. Esto formó parte del Programa Nacional de Mediación Cultural en territorios indígenas de Costa Rica del CATIE. Como afirma Mariela Leandro (comunicación personal, 8 de abril de 2018) "hubo por una parte dinero para tener gente trabajando, ir a informar, para quitarles la desconfianza".

Sin embargo, W. Philips (comunicación personal, 13 de abril de 2018) del CATIE, declara que ese "cacao criollo" es un mito ya que esas "variedades que ellos consideran como suyas son de reciente introducción" y estas comunidades indígenas se apropiaron de ellas. No obstante, existe una importante resistencia para cambiarlas lo que no permite para él que se solucione el problema central que es la baja producción y el hecho de que son pequeños productores con cultivos de subsistencia vulnerables en situación de pobreza. Para él la estrategia del CATIE fue que "el agricultor bajo su conocimiento y su propia decisión cambie la tecnología". Philips afirma que "una buena variedad puede cambiar la vida de un productor". Admite que una vez que los proyectos se van, "las estructuras desaparecen porque son paternalistas". A pesar de esto, para él solo quedan dos resultados en el campo: "el conocimiento y el material genético". Así mismo, él afirma que ellos siempre trataron de adaptarse a las posibilidades del productor y es muy riesgoso aferrarse a variedades locales que son muy susceptibles a enfermarse. Philips concluye que las variedades generadas no son perfectas, son perfectibles y que por eso la investigación en el Programa de Mejoramiento Genético es "un proceso" permanente.

Existen así dos lenguajes de valoración (Martínez Alier, 2005) divergentes, es decir dos formas de percibir y valorar la naturaleza y el cacao. Por un lado, el CATIE prioriza un lenguaje de mercado (productividad y eficiencia), mientras que en las comunidades in- 
dígenas predomina la perspectiva ecológica y espiritual (lugares sagrados, saberes tradicionales, etc.). Esto ha dificultado la comunicación y el proceso de fijar agendas políticas que sean claves para Talamanca. Los productores locales si bien, quieren vender sus cosechas a precios justos, tampoco están dispuestos a transformar de forma significativa sus fincas para mejorar su productividad. La agenda del CATIE es más compleja, pues, aunque está claro que hay un interés en generar variedades más resistentes, es evidente que las empresas donantes de los fondos también han incidido en esta agenda. Según W. Philips (comunicación personal, 13 de abril de 2018) y la página oficial del CATIE (CATIE, 2020), empresas como Hershey's invirtieron en el programa a cambio de tener acceso a variedades resistentes para distribuirlas en otros países como México y salvaguardar su producción de cacao. Y con otras empresas como Nestlé suscribieron acuerdos de confidencialidad. Para Philips este tipo de acuerdos son de ganar-ganar y así han logrado mantener este programa por más de 30 años.

Es por esto que muchas veces estas agendas externas pensadas por estas empresas y por este grupo de expertos no corresponden ni con las necesidades, ni con los imaginarios locales. Como afirma Lave (2012):

Los ecologistas políticos y los estudiosos de la naturaleza y la sociedad tienen una larga historia de estudio de la aplicación de la ciencia física ambiental para promover las agendas coloniales y neocoloniales y legitimar la apropiación estatal o corporativa de los recursos locales. ( p. 19)

Es interesante en este caso constatar cómo los procesos de producción de conocimiento científico (investigación, producción, circulación y aplicación del conocimiento), nos permiten evidenciar cómo los centros de investigación están sometidos a un proceso neoliberal en donde empresas fijan la agenda y los científicos se ven con poca capacidad de decisión (Lave, 2012). El conocimiento termina circulando y aplicándose en función de los intereses del mercado. Este fenómeno es conocido bajo el término de science regime, término que se usa para describir esta compleja relación entre la ciencia y los intereses del mercado, así como el contexto político-económico más amplio en el que se insertan estas relaciones (Lave, 2012, p. 21). Es importante aclarar que en este contexto los productores de conocimiento no son sólo los académicos sino también los actores 
locales, en este caso las comunidades indígenas. Este proceso nos permite ver cómo este conocimiento ha sido instrumentalizado no sólo para fines científicos (creación de clones y conceptos híbridos) sino para los intereses del mercado (grandes empresas chocolateras), de organizaciones internacionales, de empresas turísticas y una gran diversidad de actores. Restándole, muchas veces, importancia al conocimiento local, asignándole una categoría de valor inferior y caracterizándolo como poco eficiente. Al desligar el conocimiento de su contexto se despolitizan una serie de debates claves que son muchas veces ignorados e invisibilizados.

Es así como estamos ante una epistemología occidental que según Boaventura de Sousa Santos ha sido dominante y ha estado al servicio de intereses coloniales y capitalistas (Sousa Santos, 2010, p. 29). Para este autor, los saberes se dividen en dos, los que son visibles, inteligibles y útiles, y del otro lado los otros saberes que son invisibles, ininteligibles, peligrosos y olvidados. Esto es lo que este autor denomina como "pensamiento abismal inminentemente occidental", debido a que este tipo de pensamiento excluye al conocimiento "invisible" es decir a los saberes locales, no porque no existan sino porque sus lineamientos no son considerados como validados o verdaderos. Este pensamiento occidental basado en la ciencia no permite la coexistencia, ni la dialéctica y anula al otro conocimiento. Esta dinámica pone en práctica una intervención que es vertical y que es parte de la colonialidad del saber entendida como la hegemonía del pensamiento y la ciencia occidental-europea sobre los sujetos coloniales no occidentales (Grosfoguel, 2011) en donde se establece una jerarquía del conocimiento marcada por la raza, la clase y el género (Mignolo, 2000), dándole una posición de subordinación al conocimiento local, el cual es percibido como primitivo, amateur o supersticioso (Escobar, 2008).

\section{CONCLUSIÓN: APROPIACIÓN DE SABERES Y DISCIPLINAMIENTO ALREDEDOR DE LA PRODUCCIÓN DEL CACAO}

El análisis de las estrategias de intervención del CATIE nos ha permitido identificar múltiples procesos que ponen en evidencia cómo circulan los saberes y cómo se lleva a cabo el proceso de apropiación del conocimiento local. Es importante concluir que este proceso no es lineal, es más bien circular en donde mucho del material 
genético y del conocimiento es extraído de estos territorios. Los cuales, serán posteriormente intervenidos a través de capacitaciones que buscarán re-introducir estas "nuevas" estrategias, clones, metodologías y conceptos que fueron producidos gracias al material genético y a los saberes extraídos.

Este conocimiento extraído se utilizará para producir nuevos proyectos y programas los cuales se piensan y se diseñan desde la comunidad epistémica del cacao. Esto fue el caso del PCC, el cual fue concebido en una reunión en Noruega en el 2004 entre donantes y técnicos del CATIE, posteriormente se realizó una consulta con los socios locales por lo que se afirma que este fue el resultado de "una construcción participativa" (Somarriba et ál., 2013, p. 111). Es así como podemos concluir que estos fueron diseñados por grupos de expertos y de científicos cuyo principal objetivo era aumentar la productividad y reducir la vulnerabilidad de estos cultivos frente a enfermedades con el fin de responder a la demanda global de cacao. Muchas veces sin tomar en cuenta ni la necesidad de preservar la calidad del grano, ni las lógicas productivas tradicionales ligadas a la agricultura de subsistencia indígena. Muchos de estos programas, tampoco reflejaban las necesidades locales y las particularidades de los diferentes territorios en los que se aplican.

La identificación del origen de las fuentes de financiamiento de los proyectos, nos permitió también constatar cómo estos son financiados en su mayoría por la cooperación internacional y las empresas transnacionales. Esto pone en evidencia que a los intereses de los científicos se les agregan generalmente las agendas de estas empresas. Robinson (2013) declara que "la principal razón del auge de las ONG es que los Estados occidentales las financian" (p. 227). Los recursos de estas organizaciones provienen principalmente de los gobiernos, instituciones financieras y empresas del Norte, lo que determina una transferencia vertical de saberes a través de programas y metodologías del Norte al Sur. ¿Qué ganan estas empresas? Pues mantener la oferta de cacao y así sostener la lucrativa y creciente industria de "candy bars" y de chocolates finos. ¿Cómo? A través de la generación de plantas resistentes a enfermedades y hongos que garanticen una producción constante. Además, estas empresas han podido adquirir clones y exportarlos a otras regiones productoras de cacao. Es interesante también constatar que estas variedades modificadas genéticamente requieren de menos sombra que las variedades criollas por lo que no es necesario produ- 
cirlas en sistemas agroforestales. Esto abre la posibilidad de que se pueda producir cacao en sistemas que se asemejen cada vez más a los monocultivos.

En este sentido, las regiones donde se desarrollan estos proyectos se transformaron en verdaderos laboratorios. El CATIE, así como las otras organizaciones internacionales presentes en esta frontera (el BID, la UICN, las agencias de cooperación, entre otras) conectan a esta región fronteriza con una comunidad epistémica dedicada a la agricultura y al sector cacaotero mundial alrededor de la cual se han desarrollado todo un discurso hegemónico occidental (conceptos híbridos, metodologías, técnicas) que se ha impuesto sobre las prácticas locales.

Es interesante también observar cómo los proyectos y programas estudiados no cuestionan el modelo desarrollo hegemónico sino más bien buscan extender las lógicas capitalistas a nuevos territorios. Como bien lo plantea Robinson, la asistencia para el desarrollo siempre ha sido un instrumento de las potencias hegemónicas para tratar de abrir nuevos mercados, facilitar el acceso a los recursos naturales e integrar las regiones postcoloniales en la economía capitalista mundial (Robinson, 2003, p. 227).

En este sentido, para Chartier y Ollitrault (2005) estas organizaciones internacionales requieren mantener una imagen y credibilidad (neutralidad, interés general, respeto de los principios democráticos) para así mantener los fondos que vienen de estos donantes internacionales. Por consiguiente, sería autodestructivo para ellas apartarse demasiado radicalmente de esos registros de acción dominantes a los que se adhieren por convicción (Chartier \& Ollitrault, 2005, p. 36). Es por esto que organizaciones como el CATIE, no cuestionan las lógicas productivas dominantes como los monocultivos, sino más bien conviven con ellas.

Finalmente, podemos también concluir que la transferencia tecnológica y de conocimientos, pensada desde el CATIE y la comunidad epistémica del cacao, si bien tiene por objetivo inicial mejorar la resistencia y productividad de las variedades de cacao y responder a "las exigencias del mercado mundial" (Somarriba y Villalobos, 2013, p. 4), también, cumplió un rol "civilizatorio" y de control en las comunidades indígenas estudiadas. Es así como el análisis de los procesos de apropiación y de intervención a través de la introducción de clones, la transmisión de un vocabulario téc- 
nico (conceptos híbridos) y de metodologías de siembra y cultivo, nos permite identificar estrategias de poder y de control que tienen un objetivo civilizatorio que busca disciplinar e insertar a estas comunidades indígenas en las lógicas productivas y de mercado.

A través de la generación de todo un lenguaje técnico (conceptos híbridos) y científico se "des-naturalizó a la naturaleza" y se le volvió un objeto de conocimiento y materia prima del proceso productivo (Leff, 2003, p. 22). Estamos así frente a un conflicto entre diferentes formas de valorizar lo cotidiano y la naturaleza, en donde no se reconoce los saberes tradicionales y los derechos indígenas. Estas intervenciones y apropiaciones buscan modificar la forma en que estas comunidades perciben y viven la naturaleza y el cacao. Leff (2013), hace alusión a la noción de pensamiento único y unidimensional el cual está sustentado en la ciencia, la racionalidad occidental, la productividad económica y la eficiencia tecnológica. Este pensamiento que se presenta a sí mismo como universal ha buscado recodificar "al mundo y los mundos de vida en términos de valores de mercado" (Leff, 2003, p. 24). Como bien subraya Escobar (2006, p. 9), "el poder habita a los significados y los significados son la fuente del poder".

Si bien muchos de las y los entrevistados "aceptaron" introducir estos clones y las estrategias producidas por el CATIE, muchos cuestionan la calidad del grano resultante y la forma a través de la cual se les capacitó sin reconocer sus saberes ni experiencias. Leff describe a este proceso como un proceso de "homogeneización forzada" que no permite "el derecho a ser", a ser diferente y a "disentir de los sentidos preestablecidos y legitimados por poderes hegemónicos" (Leff, 2003, p. 27).

\section{BIBLIOGRAFÍA}

Acuña, K. (2007). Tsuru: El cacao en Alta Talamanca. Revista Herencia. 20 (1,2), 83-98. https://revistas.ucr.ac.cr/index.php/herencia/article/ viewFile/10035/9440

Allard, P., Smadja, J. y Roué, M. (2006). Rôle du politique, de l'Etat et des groupes sociaux dans le discours sur la crise environnementale. En C. Beck et ál. (Eds.), Temps et espaces des crises de l'environnement (pp. 301-312). Editions Quae. 
Altieri, M. A. (2009). Agroecología, pequeñas fincas y soberanía alimentaria. Ecología política, 38, 25-35.

Borge, C. y Castillo, R. (1997). Cultura y conservación en la Talamanca indígena. Sociedad de Estudios para el Desarrollo Rural. https://books. google.co.cr/books?id=2KjvCHjcm8UC

Borge, C. y Castillo, R. (1997). Cultura y conservación en la Talamanca indígena. EUNED.

Bossy, T. y Evard, A. (2010). Communauté épistémique. En L. Boussaguet (Ed.), Dictionnaires des politiques publiques (pp. 140-141). Presses de Sciences Po.

Bourgois, P. (1994). Banano, etnia y lucha social en Centro América. Editorial Department Ecuménico de Investigaciones.

Boza Villarreal, A. (2014). La frontera indígena de la Gran Talamanca, 18401930. (EUCR-EUNED).

Bozzoli, M. E. (1979). El nacimiento y la muerte entre los bribris. Anuario De Estudios Centroamericanos, 6(1), 117. https://revistas.ucr.ac.cr/index.php/anuario/article/view/3030

Carmagnani, M. (2008). La agricultura familiar en América Latina. Problemas del desarrollo, 39(153), 11-56.

Estrada, Romero, Moreno (2011). Guía técnica del cultivo del cacao manejado con técnicas agroecológicas. CATIE. http://infocafes.com/ portal/wp-content/uploads/2016/01/Estrada_et_al_Guia_Tecnica_ Cacao.pdf

CATIE (2019). Programa mejoramiento genético del cacao. https:/ / www.catie. ac.cr/productos-y-servicios/consultorias-y-servicios-de-alto-nivel/ mejoramiento-genetico/programa-mejoramiento-genetico-del-cacao. html

CATIE. (2020). Fórmula Perfecta, colaboradores y aliados, socio y donantes. https://www.catie.ac.cr/que-es-catie/formula-perfecta-colaboradores-y-aliados/socios-donantes.html

Chartier, D. y Ollitrault, S. (2005). Les ONG d'environnement dans un système international en mutation: Des objets non identifiés? En Catherice Aubertin (Ed), Représenter la nature? ONG et biodiversité (pp. 21-58). IRD Editions.

Chavarochette, C., y Rodriguez, T. (2020). Les territoires du cacao biologique, alternatives productives et femmes indigènes, Talamanca, Costa Rica. Études caribéennes, 45-46. https://doi.org/10.4000/etudescari- 
beennes.18486

Escobar, A. (2008). Territories of difference: Place, movements, life, redes. Duke University Press.

Escobar, A. (2006). An ecology of difference: Equality and conflict in a glocalized world. Focaal, (47), 120-137.

FAO. (2020). Antecedentes | Plataforma de conocimientos sobre agricultura familiar | Organización de las Naciones Unidas para la Alimentación y la Agricultura. http://www.fao.org/family-farming/background/es/

Franklin, H. (2007). Costa Rica-Panama, Gestión Integrada de ecosistemas en la Río Sixaola. Documento de Proyecto. Banco Interamericano de Desarrollo.

Gago, V. y Mezzadra, S. (2015). Para una crítica de las operaciones extractivas del capital. Patrón de acumulación y luchas sociales en el tiempo de la financiarización. Nueva sociedad, 255, 38-52.

Giraldo, O. F. (2018). La ecología política de la agricultura. Agroecología y posdesarrollo. El Colegio de la Frontera Sur.

Grosfoguel, R. (2011). Decolonizing Post-Colonial Studies and Paradigms of Political-Economy: Transmodernity, Decolonial Thinking, and Global Coloniality. TRANSMODERNITY: Journal of Peripheral Cultural Production of the Luso-Hispanic World, 1(1). https://escholarship.org/ uc/item/21k6t3fq

Guevara, F. (2011). Cronología básica de los pueblos indígenas de Costa Rica: Desde los inicios del siglo XVI hasta el año 2000. San José, Costa Rica: Siwä Pakö.

Guiracocha, G., Harvey, C., Somarriba, E., Krauss, U., y Carrillo, E. (2001). Conservación de la biodiversidad en sistemas agroforestales con cacao y banano en Talamanca, Costa Rica. Agroforestería en las Américas, $8(30)$.

Haas, P. (1992). Introduction: Epistemic Communities and International Policy Coordination. International Organization, 46(1), 1-37.

Haas, P. (2013). Epistemic Communities. En Joel Krieger (Ed.), The Oxford Companion to Comparative Politics (pp. 351-359). Oxford University Press.

Hall, C. (1985). America Central como región geográfica. Anuario de Estudios Centroamericanos, 11(2), 5-24.

Hall, C., Perez Brignoli, H. y Cotter, J. V. (2003). Historical Atlas of Central 
America. University of Oklahoma Press.

Hassenteufel, P. (2011). Sociologie de l'action publique. Armand Colin.

Krauss, U., Arroyo, C., García, J., Portuguez, A. y Sánchez, V. (2003). Manejo integrado de la moniliasis (Moniliophthora roreri) del cacao (Theobroma cacao) en Talamanca, Costa Rica. Agroforesteria en las Américas, 10(37-38), 52-58.

Lave, R. (2012). Neoliberalism and the Production of Environmental Knowledge. Environment and Society, 3(1), 19-38. https://doi. org/10.3167/ares.2012.030103

Leff, E. (2003). La Ecología Política En América Latina. Un Campo En Construcción. Polis, 2(5), 125-145.

Llaguno Thomas, J. J., Solano, S. M., Espeleta, A. L. G., Alfaro, P. B. y Moraga, F. M. (2014). Políticas y conflictos socio ambientales: El caso de la tenencia de la tierra y los monocultivos en el caribe de Costa Rica (2006-2012). Revista de Ciencias Sociales, 0(145). http://revistas.ucr.ac. cr/index.php/sociales/article/view/17612

MacLeod, P. (1996). Auge y estancamiento de la producción de cacao en Costa Rica 1660-95. Anuario de Estudios Centroamericanos, 22(1), 83107.

Martínez Alier, J. (2005). El ecologismo de los pobres. Conflictos Ambientales y lenguajes de valoración. Icaria Antrazyt- FLACSO. http://www.terra. org/categorias/libros/el-ecologismo-de-los-pobres

Meyer, M. y Molyneux-Hodgson, S. (2011). "Communautés épistémiques": Une notion utile pour théoriser les collectifs en sciences? Terrain et Travaux, 18(ENS Cachan), 141-154.

Mignolo, W. D. (2000). La colonialidad a lo largo y a lo ancho: El hemisferio occidental en el horizonte colonial de la modernidad. En E. Lander (Ed.), La colonialidad del saber: Eurocentrismo y ciencias sociales. CLACSO.

Ministerio de Agricultura y Ganaderia. (2018). Plan Nacional de Cacao 2018-2028. Hacia la consolidación de una agrocadena competitiva y sostenible. http:/ /www.mag.go.cr/bibliotecavirtual/E14-11072.pdf

Ojeda, D. (2016). Los paisajes del despojo: Propuestas para un análisis desde las reconfiguraciones socioespaciales. Revista Colombiana de Antropología, 52 (2), 19-43. https://doi.org/10.22380/2539472X.27

Perez Brignoli, H. (2000). Breve historia de Centroamérica. El libro de bolsillo; Alianza Editorial. 
Quesada, J. R. (1987). Cacao en la zona atlántica 1821-1935 (informe de Investigación Núm. 36). Universidad de Costa Rica. https://repositorios.cihac.fcs.ucr.ac.cr/repositorio/handle/123456789/385

Robinson, W. I. (2003). Transnational conflicts: Central America, social change and globalization. Verso.

Rodríguez Echavarría, T. (2018). Mitos y realidades de la gobernanza del agua en la cuenca transfronteriza del Rio Sixaola. En Kauffer (Ed), Cuencas transfronterizas: la apertura de la presa del nacionalismo metodológico. Ciudad de México, CIESAS.

Rodríguez Echavarría, T. (2019). Gobernanza ambiental en cuencas transfronterizas: La cuenca del río Sixaola (Costa Rica-Panamá). Iztapalapa. Revista de Ciencias Sociales y Humanidades, 40(87), 71-99.

Rodríguez Echavarría, T. (2013). Dynamiques de coopération transfrontalière sur la façade caraïbe du Costa Rica et du Panama: Le cas du bassin du fleuve Sixaola. Études caribéennes, 20, 1-20. https://doi. org/10.4000/etudescaribeennes.5747

Rodriguez Echavarría, T. (2014). Gouverner l'environnement dans des régions frontalières. Coopération et conflits dans les bassins du fleuve San Juan (Costa Rica-Nicaragua) et du flueve Sixaola (Costa Rica-Panama) [Thèse de Doctorat en Géographie, Université Paris Diderot- Paris]. Paris 7Diderot. http:// kerwa.ucr.ac.cr/handle/10669/76687?show =full

Rodríguez-Sperat, R. y Emanuel-Jara, C. (2018). Eficiencia y agricultura familiar: Más de un siglo de debate sin suficientes respuestas. Agricultura, sociedad y desarrollo, 15(4), 595-617.

Rosés Alvarado, C. (1982). El ciclo del cacao en la economía colonial de Costa Rica, 1650-1794. Mesoamérica, 3(4), 247-278.

Royo, A. (2004). La ocupación del Pacífico Sur costarricense por parte de la Compañía Bananera (1938-1984). Diálogos Revista Electrónica, 4(2), 154-167. https://doi.org/10.15517/dre.v4i2.6281

Salazar-Díaz, R. (2011). Caracterización de Sistemas Agroecológicos para el establecimiento comercial de cacao orgánico (Theobroma cacao) en Talamanca. [tesis de maestría, Instituto Tecnológico de Costa Rica] Repositorio de ITCR. http:/ /hdl.handle.net/2238/6272

SEPSA. (2017). Análisis de la actividad cacaotera costarricense y perspectivas de su reactivación. Secretaría Ejecutiva de Planificación Sectorial Agropecuaria.

Sevilla, E. (2006). Agroecología y agricultura ecológica: Hacia una "re" 
construcción de la soberanía alimentaria. Agroecología, 1, 12.

Somarriba, E. y Harvey, C. (2002, octubre). Cacao, biodiversidad y pueblos indígenas producción sostenible y conservación de la biodiversidad en fincas cacaoteras de Talamanca [ponencia]. IV Congresso Brasiliero de Sistemas Agroflorestais, Ilheus, Bahia, Brasil. https://www.researchgate. net/publication/324213165_Cacao_biodiversidad_y_pueblos_indigenas_produccion_sostenible_y_conservacion_de_la_biodiversidad_ en_fincas_cacaoteras_de_talamanca

Somarriba, E. y Villalobos, M. (2013). La contribución del Proyecto Cacao Centroamérica el estímulo del sector cacaotero de Centroamérica. Agroforestería en las Américas, 49, 4-6.

Somarriba, E., Villalobos, M., Cerda, R., Astorga, C., Orozco, S., Escobedo, A., Say, E., Deheuvels, O., Orozco, L., Junkin, R., Villegas, R., López, A. y Salazar, J. (2013). ¿Cómo diseñamos y ejecutamos el Proyecto Cacao Centroamérica para estimular al sector cacaotero de Centroamérica? Agroforestería en Las Américas, 49, 111-127.

Somarriba, E., Villalobos, M., González, J. y Harvey, C. (2004, 11-12 marzo). El proyecto conservación de biodiversidad y producción sostenible en pequeñas fincas indígenas de cacao orgánico en el corredor biológico Talamanca-Caribe, Costa Rica [conferencia]. Semana Científica, CATIE, Turrialba, Costa Rica.

Soto Noriega, M. (2006). Transferencia tecnológica, ¿Qué podemos aprender de la experiencia internacional? Journal of Technology Management E Innovation, 1(3), 1-3.

Sousa Santos, B. (2010). Descolonizar el saber, reinventar el poder. Ediciones Trilce-Extensión universitaria, Universidad de la República.

Taylor, P. J. y Flint, C. (1994). Geografía política: Economía mundo, estado-nación y localidad. Trama.

Viales Hurtado, R. (2006). Más allá del enclave en Centroamérica: Aportes para una revisión conceptual a partir del caso de la región Caribe costarricense (1870-1950). Iberoamericana (2001-), 6(23), 97-111.

Viales Hurtado, R.J. (1998). Después del enclave, 1927-1950. Editorial UCR.

Viales Hurtado, R.J. (2016). La región Atlántico-Caribe de Costa Rica: Las imágenes de la construcción regional. Memorias, 30, 219-233.

Viales Hurtado, R. J. (2003). La especialización productiva agropecuaria regional en Costa Rica. 1870-1950. Una propuesta de análisis a partir del caso de la región Atlántica. Revista de Historia , 47, 11-41. 
Villalobos, V. y Borge, C. (1995). Talamanca en la encrucijada. Editorial UNED.

TANIA RODRÍGUEZ ECHAVARRÍA es costarricense. Doctora en Geografía de los Países Emergentes por la Universidad Paris 7, Paris Diderot. Docente e investigadora en propiedad de la Escuela de Ciencias Políticas y la Escuela de Geografía de la Universidad de Costa Rica. Actualmente dirige la Maestría en Ciencias Políticas en la misma universidad. 